\title{
MODERNIZAÇÃO E RELAÇÕES DE TRABALHO NA AGRICULTURA
}

BRASILEIRA*

MODERNIZATION AND WORK RELATIONS IN THE BRAZILIAN

AGRICULTURE

MODERNIZACIÓN Y RELACIONES DE TRABAJO EN LA AGRICULTURA

BRASILEÑA

Rodrigo Constante Martins

Professor do Programa de Pós Graduação em Ciências Sociais da Universidade Federal de São Carlos e pesquisador convidado da Maison des Sciences de l’Homme, França (Programme Hermes 2005-2006). E-mail: rodrigo@iris.ufscar.br

\section{Resumo}

A elaboração de conceitos teóricos sobre a chamada industrialização da agricultura brasileira envolve a contextualização analítica mais ampla dos processos agrários. Para além das explicações sobre o aprofundamento das relações entre indústria e agricultura, a produção conceitual acerca deste processo gerou impactos substantivos sobre a própria constituição dos discursos políticos em torno da transição do trabalho rural no país para uma etapa eminentemente moderna. O objetivo deste artigo é realizar uma revisão crítica da formulação do conceito industrialização da agricultura, dando ênfase às implicações desta abordagem conceitual nas análises sobre as relações de trabalho na agricultura brasileira. Faremos o uso analítico da categoria marxista de totalidade como proposta de construção de abordagens concretas sobre as especificidades das relações de trabalho produzidas no movimento de modernização da agricultura nacional.

Palavras-chave: relações de trabalho na agricultura; trabalho e capitalismo; agricultura e capitalismo; modernização da agricultura; trabalho, natureza e agricultura

\footnotetext{
Abstract

The theoretical construction of concepts about the called industrialization of the Brazilian agriculture involves the wide analytic treatment of the agrarian processes. Besides the explanations on the deepening about the relationships between industry and agriculture, the conceptual production concerning this process generated substantive impacts about the own constitution of the political discourses around the transition of
} 
the rural work in Brazil to one stage eminently modern. The objective of this article is to make a critical revision on the formulation of the concept industrialization of agriculture, giving emphasis in the implications of this conceptual approach on analyses about the work relations in Brazilian agriculture. We will utilize the Marxist analytical category of the totality for the construction of concrete approaches about the particularities of the work relations produced in the movement of modernization on Brazilian agriculture.

Key-words: work relations in the agriculture; work and capitalism; agriculture and capitalism; modernization of agriculture; work, nature and agriculture.

\section{Resumen}

La elaboración de conceptos teóricos sobre la llamada industrialización de la agricultura brasileña implica una contextualización más amplia de los procesos agrarios. Más allá de las explicaciones sobre la profundización de las relaciones entre industria y agricultura, la producción conceptual acerca de este proceso generó impactos sustantivos sobre la propia constitución de los discursos políticos en torno de la transición del trabajo rural en el país hacia una etapa eminentemente moderna. El objetivo de este trabajo es revisar críticamente la formulación del concepto industrialización de la agricultura, haciendo énfasis en las implicaciones de este abordaje conceptual en los análisis de las relaciones de trabajo en la agricultura brasileña. Haremos un uso analítico de la categoría marxista de totalidad como propuesta para la construcción de abordajes concretos de las especificidades de las relaciones de trabajo producidas en el movimiento de modernización de la agricultura nacional.

Palabras llave: relaciones de trabajo en la agricultura; trabajo y capitalismo; agricultura y capitalismo; modernización de la agricultura; trabajo, naturaleza y agricultura.

\section{Introdução}

Ao longo do século XX, foi notória a aproximação estabelecida entre a agricultura e os demais setores da economia. Integrada cada vez mais ao processo industrial de produção de valores excedentes, a agricultura capitalista incorporou, neste 
período, incrementos tecnológicos decisivos para a consolidação de um movimento de relativização das "barreiras" naturais que se colocavam à sua produção intensiva.

Como é sabido, ao contrário da indústria, a produção agrícola tem como uma das suas principais características a descontinuidade da ação do trabalho humano no seu interior devido à sua dependência para com os fenômenos naturais. Tanto o ritmo biológico do ciclo de crescimento das plantas quanto os fatores climáticos do local de produção determinam a forma de ação do trabalho. Além de o processo produtivo possuir datas pré-determinadas de início e término, condicionadas pelos fatores supra, ocorre que ele não pode ser interrompido pelo exclusivo arbítrio social. Dada a natureza sequencial das etapas produtivas e a dispensa do trabalho humano para algumas delas, a produção agrícola assume uma singularidade que não permite o pleno controle externo das suas atividades. A rigidez desta ordem seqüencial limita, inclusive, o próprio alcance do progresso técnico no setor.

No Brasil, especialmente a partir da segunda metade do século XX, a aliança entre a agricultura e os capitais industriais, ao confrontar o objetivo da acumulação com os limites naturais da produção agrícola, dirigiu suas ações para a maximização do controle dos processos naturais e para a conquista de novos espaços de produção de valores excedentes. Neste caso, sua expansão sobre as áreas rurais deu-se, no mais das vezes, mediante a conciliação dos interesses da grande propriedade agrícola com aqueles da manutenção das circunstancias locais de domínio e desigualdades sociais, constituindo assim o que convencionou-se chamar de modernização conservadora das áreas rurais.

A análise deste fenômeno na agricultura brasileira já produziu um amplo debate teórico-conceitual. Trabalhos de expressão cunharam o termo industrialização da agricultura para expor as características fundamentais deste movimento (GRAZIANO DA SILVA, 1981; GUIMARÃES, 1982; KAGEYAMA, 1990). A despeito de suas ambivalências - abordadas por autores como Veiga (1991) e Abramovay (1992) - tal conceito ganhou notoriedade em parcela significativa dos estudos sobre as temáticas agrícola e agrária no país. Ademais, suas possibilidades analíticas forneceram as bases para a consolidação da interpretação de supostas insuficiências do processo de modernização da agricultura nacional - insuficiências marcadas, sobretudo, pelo emprego temporário da força de trabalho na produção imediata. 
Neste artigo, procuraremos examinar criticamente a construção desta alternativa conceitual. Pretendemos, mais especificamente, demonstrar como permanece insuficiente o modo como tal enfoque aborda as transformações das relações de trabalho na agricultura brasileira. Para tanto, faremos um breve resgate do debate conceitual travado em torno das mudanças tecno-produtivas na agricultura moderna, tomando por referência os termos empreendidos pelos estudiosos do caso brasileiro. Posteriormente, tentaremos recuperar a perspectiva da categoria marxista de totalidade para a compreensão das especificidades da modernização da agricultura nacional, atentando especialmente para aquelas características que se destacam, na análise dialética, como determinações particulares da reprodução de contextos mais amplos de sociabilidade; ou, nos termos de Castells (2001), da reprodução dos modos de organização da experiência social e das relações de poder que lhes são intrínsecas sobre os espaços, sejam estes últimos de fluxos ou de lugares.

\section{A problemática da industrialização da agricultura}

O termo industrialização da agricultura tornou-se corrente nas ciências sociais brasileiras para caracterizar as transformações ocorridas no processo de produção agrícola ao longo dos últimos 50 anos. Entretanto, o mesmo tornou-se fonte de polêmica, possibilitando, assim, o surgimento de uma diversidade de análises, ora reforçando a sua utilidade, ora contestando-a.

Para Alberto Passos Guimarães, um dos estudiosos que mais contribuíram para a análise da questão agrária no país, a transformação das forças produtivas industriais teria sido o elemento propulsor dos processos modernos de produção agrícola. De acordo com o autor, à medida em que os conhecimentos técnicos e científicos da indústria foram se ampliando, abriu-se o caminho para um salto qualitativo da produção agrícola no sentido da melhoria de sua produtividade e do aumento da produção propriamente dita. Se no passado ter sido a revolução agrícola a responsável pela abertura do caminho à revolução industrial, formando mercados para 0 consumo das manufaturas, na segunda metade do século XX seria "o desenvolvimento industrial o responsável pela dinâmica do desenvolvimento agrícola, ditando à agricultura as regras segundo as quais esta poderia progredir, bem como os limites até onde poderia expandir-se" (GUIMARÃES, 1982: 83) 
Segundo Guimarães, este não seria um processo no qual a agricultura estaria industrializando-se, mas sim uma etapa em que a indústria estaria industrializando a agricultura. Tal etapa seria caracterizada por dois momentos: um primeiro, denominado industrialização espontânea, teria se iniciado com o uso de uma tecnologia incipiente, expressada pelos adubos naturais (orgânicos e minerais) e pelos arados e outros implementos operados pela força animal em substituição à força humana; um segundo momento, chamado de industrialização dirigida, teria surgido com a substituição dos adubos naturais pelos adubos artificiais e da maquinaria agrícola simples por equipamentos complexos, ambos provenientes de indústrias de grande porte, dotadas de alto nível tecnológico:

"Com a implantação de um parque industrial de grande magnitude, especializado na produção de equipamentos e insumos agrícolas de alta complexidade (...), cria-se uma situação qualitativamente diferente, que se caracteriza pela dependência cada vez maior da agricultura à grande indústria (e paralelamente ao grande capital urbano-industrial), pela integração das duas atividades através de vínculos contratuais ou orgânicos, e que conduzem à formação do complexo agroindustrial" (GUIMARÃES, 1982: 92).

Desta maneira, o surgimento dos complexos agroindustriais seria, para Guimarães, a expressão final de um processo evolutivo da atividade agrícola que, após ser industrializada a partir de elementos determinantes da própria indústria, culminaria com a integração destas duas esferas produtivas. Em outras palavras, tratar-se-ia do processo o qual Kautsky (1970) chamou de supressão do divórcio entre indústria e agricultura.

Graziano da Silva (1996) também compartilhou desta concepção de que haveria dependência do padrão agrícola moderno para com a indústria. De acordo com o autor, para além do simples consumo de bens industriais pela agricultura, a industrialização desta caracterizar-se-ia como o momento decisivo da perda de autonomia de seu próprio desenvolvimento; a partir de então, a agricultura teria sua dinâmica atrelada às demandas dos setores industriais. Neste movimento estaria estabelecida sua submissão à indústria, a qual passaria a comandar a direção, as formas e o ritmo das transformações operadas na base de produção agrícola. $\mathrm{O}$ entendimento do 
autor estaria intimamente ligado à apreensão do fenômeno de constituição dos Complexos Agroindustriais ${ }^{1}$ :

“A constituição dos CAIs e a industrialização da agricultura passam a ser os novos determinantes da dinâmica da agricultura. (...) A partir desse momento o desenvolvimento da agricultura não é mais autônomo, mas passa a depender da dinâmica da indústria; não se pode mais falar da agricultura como "grande setor" na economia (como na divisão tradicional agricultura-indústria-serviços), porque grande parte das atividades agrícolas integrou-se profundamente na matriz de relações interindustriais, sendo seu funcionamento determinado de forma conjunta." (GRAZIANO DA SILVA, 1996: 3233)

Neste mesmo sentido, seguiram Kageyama et al (1990), que atribuíram ao conceito industrialização da agricultura a pertinência de demonstrar a maneira pela qual a agricultura teria se transformado num ramo de produção semelhante a uma indústria, atrelando-se mais intensamente ao movimento geral de valorização capitalista. Seja comprando insumos industriais ou produzindo matérias-primas para indústrias de transformação, a agricultura estaria submetendo-se ao domínio do capital industrial tanto no que tange ao predomínio de suas relações sociais de produção quanto no que se refere à superação dos obstáculos representados pela natureza ao seu processo de valorização.

"O longo processo de transformação da base técnica - chamado de modernização - culmina na própria industrialização da agricultura. Esse processo representa a subordinação da natureza ao capital que, gradativamente, liberta o processo de produção agropecuária das condições naturais dadas, passando a fabricá-las sempre que se fizerem necessárias" (KAGEYAMA et al., 1990: 114).

\footnotetext{
${ }^{1}$ Por conta deste movimento, autores como Muller (1989), Kageyama (1990) e o próprio Graziano da Silva (1996) propõem que os Complexos Agroindustriais devam ser entendidos como unidade de análise do moderno padrão de relações da agricultura brasileira.
} 
Concordando com parte desta argumentação, Szmrecsányi (1990), por sua vez, afirmou que o conceito industrialização da agricultura deveria referir-se essencialmente à adaptação das formas de produção da indústria aos processos produtivos do setor agropecuário, adaptação esta que, longe de significar que a indústria se quede aos requerimentos da agricultura, demonstra exatamente o seu contrário: a indústria se adapta a eles para que seus tentáculos se expandam sobre setores até então fora de seus domínios. A agricultura transformar-se-ia, por envolvimento, em indústria, mas, conforme observa o autor, não viria a ser um ramo industrial como outro qualquer, visto que o alcance de tais transformações ainda estaria por ser examinado.

Não obstante a evidência da parceria subordinada da produção agrícola com os interesses industriais, alguns teóricos contestaram a pertinência do termo industrialização da agricultura para exprimir o devir da agricultura. De um modo geral, tais contestações foram balizadas pelo seguinte questionamento: a natureza se subordinará ao capital irremediavelmente, a ponto do termo industrialização da agricultura abranger a compreensão do futuro mais remoto desta parceria?

Refletindo sobre esta questão, Veiga (1991) afirmou que a retomada da discussão acerca das especificidades do setor agrícola frente a outras esferas produtivas teria que transcender ao conceito industrialização da agricultura, posto que o mesmo revelaria um certo "otimismo" em relação à capacidade do capital em superar os limites que a natureza impõe ao seu processo de valorização na produção agrícola. Isso sem falar na importância implícita que este termo concede ao papel do trabalho direto no interior da própria produção agrícola. Se, na indústria, o trabalho humano teria a função de transformar uma matéria-prima em um novo produto, na agricultura o trabalho humano poderia somente sustentar ou regular condições específicas sob as quais as plantas crescem e se reproduzem. A etapa de transformação neste processo estaria necessariamente sob o comando de mecanismos orgânico-naturais e não do trabalho humano, como o é na indústria. Nos termos do autor,

“O papel do homem na produção agropecuária consiste em fornecer aos organismos vivos as condições que mais favoreçam o seu desenvolvimento, para depois colher a massa de matéria nutritiva produzida. Mas o essencial dessa operação, isto é, a produção dessa matéria nova, é realizado pelos próprios organismos vivos." (VEIGA, 1991: 177) 
A própria noção de Complexo Agroindustrial poderia - segundo Veiga - ser útil na tentativa de criação de tipologias que pudessem auxiliar na apreensão da relação agricultura-indústria no interior de determinados segmentos produtivos, mas de maneira alguma poderia ser entendida enquanto uma teorização acabada a respeito da dinâmica de tais relações.

Para Veiga, uma forma mais adequada para se compreender o real conteúdo da relação agricultura-indústria seria a partir dos conceitos apropriacionismosubstitucionismo de Goodman, Sorj e Wilkinson (1990), os quais possibilitariam a superação da noção de industrialização da agricultura através de uma análise histórica da aproximação das produções agrícola e industrial.

De acordo com Goodman, Sorj e Wilkinson (1990), em sua busca incessante por movimentos mais amplos de valorização, o capital industrial teria pretendido, na agricultura, maximizar seu controle sobre os processos naturais, de tal modo que ele próprio pudesse assegurar novos espaços de valorização e reprodução de suas relações. Neste caso, a noção de apropriacionismo representaria um movimento de apropriação industrial de frações do processo de produção agrícola superando restrições ambientais - sendo que uma de suas principais expressões seria a mecanização dos instrumentos de trabalho necessários ao preparo do solo -, enquanto que $\mathrm{o}$ substitucionismo evidenciaria um momento em que o produto agrícola passaria cada vez mais a ser substituído por produtos industriais - evidência que poderia ser notada a partir do desenvolvimento recente da indústria alimentícia. Desta maneira, para estes autores, "apropriacionismo e substitucionismo seriam a resposta industrial específica à resistência do processo biológico da produção agrícola à transformação industrial direta” (GOODMAN, SORJ, WILKINSON, 1990: 89).

Neste mesmo movimento, as modernas biotecnologias teriam trazido um importante avanço na capacidade dos capitais industriais ampliarem seu controle sobre o ciclo biológico da produção agrícola. Tal avanço marcaria o surgimento de uma etapa de manipulação industrial generalizada da natureza sob o comando da engenharia genética, possibilitando assim o reforço dos padrões de apropriacionismo e substitucionismo na agricultura moderna. No que se refere ao primeiro, tem-se a possibilidade, a partir de alterações no código genético das plantas, de se tentar criar sistemas agrícolas automatizados e de produção contínua. Quanto ao substitucionismo, os autores observam, nas tendências gerais do desenvolvimento biotecnológico, a possibilidade de um distanciamento cada vez maior por parte da indústria alimentícia 
frente à agricultura convencional na medida em que os avanços de conhecimento sobre as manipulações de processos químicos possibilitam a criação de "ambientes artificiais" para a produção de alimentos, caracterizando assim a chamada bioindustrialização. Este fato poderia vir a romper conexões estratégicas de cadeias agroalimentares, gerando uma espécie de trivialização do produto agrícola.

Do ponto de vista conceitual, é importante destacar que, assim como afirma Veiga, os conceitos apropriacionismo e substitucionismo abarcam elementos fundamentais para o entendimento do processo de capitalização da atividade agrícola. De fato, o pressuposto de uma industrialização do processo de produção agrícola confronta-se com as particularidades que os processos biológicos impõem à própria agricultura. Por certo, a situação geográfica do espaço caracteriza-o como ambiente, apresentando condições e características naturais especiais, com graus de fertilidade, variações de clima, disponibilidade de recursos hídricos, entre outros, muito particulares, os quais formam sinergias que determinam inputs tecnológicos diferenciados, como diferenciado também é o trabalho direto aplicado sobre as lavouras. Assim, pensar a industrialização da agricultura como um processo social e econômico de absorção completa da lógica produtiva da indústria pela agricultura é deixar de considerar, dentre outros aspectos, a dimensão ambiental que está imbricada na produção.

\section{As determinações particulares do capitalismo na agricultura}

Alguns dos limites das interpretações baseadas na abordagem conceitual da industrialização da agricultura tornam-se mais evidentes quanto confrontamos estas interpretações com os objetivos de construção de análises concretas propostos pelo materialismo dialético. Neste caso, uma questão em especial revela dificuldades substanciais na referida abordagem para a interpretação histórica sobre as formas sociais de uso e acesso aos recursos naturais. Tal questão diz respeito ao modo como o trabalho social é concebido no espectro da teorização sobre a industrialização das práticas agrícolas. 
Se partirmos da relação dialética em que Marx (1987) aponta o trabalho como categoria fundamental para se apreender as manifestações essenciais das formas de reprodução de um conjunto social - e o fundamental aqui deve ser entendido enquanto determinação irredutível ${ }^{2}$-, torna-se imprescindível a compreensão do conteúdo particular que o trabalho assume em situações históricas específicas. Conforme vimos, na agricultura capitalista, a relação trabalho-natureza apresenta uma importante especificidade que não pode ser descartada: a transformação da matéria prima em mercadoria não é realizada exclusivamente pelo trabalho humano, mas sim através da combinação de seu exercício com o ritmo biológico das forças naturais ${ }^{3}$. Sem embargo, isto confere aos processos ecossistêmicos uma dimensão decisiva no âmbito da produção de valores na agricultura. Do ponto de vista analítico, tais processos adquirem um conteúdo histórico que ultrapassa a simples condição de base biofísica dos processos de acumulação. Conforme ressalta Leff (2001: 73-74):

“(...) se a formação do valor surge como o centro organizador dos processos produtivos do capital, seu meio está conformado pelos processos ecossistêmicos de produção e regeneração de um sistema de recursos que, ao não incorporar trabalho vivo, são carentes de valor. Entretanto, a dotação de recursos, sua capacidade de regeneração e sua produtividade ecológica, os limites para as taxas e os ritmos de exploração dos recursos fixados pela resiliência e a capacidade de carga do meio condicionam o processo de valorização, de acumulação e reprodução do capital.”.

Considerando a importância das variáveis ecológicas na produção de valor, cumpre também destacar que a composição particular estabelecida entre a

\footnotetext{
${ }^{2} \mathrm{Na}$ dialética marxista, a busca analítica das determinações simples, dos elementos irredutíveis de totalidades históricas, é o fundamento da construção de análises concretas sobre a realidade social. Isto significa, portanto, que as determinações simples aqui referidas em nada se aproximam dos métodos de causalidade social empregados pelas correntes deterministas das ciências sociais. Diferem, portanto, de esforços interpretativos tais como a teoria dos jogos, na qual fatos são relacionados de tal modo que, através de proposições gerais e normas relativas a seu quadro de referência e conteúdo, venha a instalar-se entre os elementos próprios do sistema descritivo uma relação de implicação lógica. Ao contrário disso, as determinações simples, apontadas por Marx (1983), dizem respeito justamente às relações elementares da vida cotidiana, que são reconstituídas, através do movimento dialético, em redes mais amplas de relações e novas determinações.

${ }^{3}$ A propósito do debate recente sobre o avanço das relações capitalistas em direção à mercantilização dos próprios recursos naturais, ver Martins (2004).
} 
configuração territorial - formada pelos objetos da natureza e por suas funções ecossistêmicas - e a esfera social, formada pelo conjunto de relações que definem uma sociedade em um dado momento histórico, pode influir decisivamente no regime de acumulação ${ }^{4}$ na agricultura. Tal fator, entretanto, parece não ter sido devidamente considerado nas abordagens sobre a industrialização da agricultura quando estas se dedicaram, por exemplo, à análise da sazonalidade no emprego da força de trabalho agrícola. De acordo com Graziano da Silva (1981), autor que dedicou-se com profundidade às questões relativas ao emprego agrícola, o trabalho temporário sazonal foi uma estratégia eficiente do capital, num momento histórico específico, para solucionar o impasse colocado pelo processo produtivo agrícola reduzindo a disfunção entre tempo de trabalho e tempo de produção. Mesmo assim, o trabalho temporário na agricultura seria um forte indício da insuficiência e fraqueza do desenvolvimento capitalista na produção agrícola, uma vez que, por representar as discrepâncias existentes entre os tempos de trabalho necessários às diversas fases que envolvem o período de produção - plantio, tratos culturais e colheita -, o mesmo evidenciaria fragilidades que dificultariam a total subordinação da natureza ao capital.

Conforme o próprio autor,

"É interessante observar que as opções de mecanização de colheita existem para as culturas como trigo e soja, mas não para as tipicamente tropicais, como o café e a cana-de-açúcar. Apenas depois da $2^{\text {a }}$ Guerra Mundial é que se iniciaram as tentativas de adaptar uma colhedeira de cereja dos EUA para colher café no Brasil; e de uma colhedeira de cana a partir de máquinas desenvolvidas na Austrália. A explicação para isso parece estar no fato de que as transformações que o capital provocou na agricultura inglesa e norte-americana levaram realmente à revolução da produção agrícola em si mesma. Já as colônias de exploração, como o Brasil e demais países da América

\footnotetext{
${ }^{4}$ Por regime de acumulação, tomamos a definição de Benko (1996: 244) que o designa como “o conjunto das regularidades que asseguram a progressão geral e relativamente coerente de acumulação do capital, isto é, que permitem assimilar ou desdobrar no tempo as distorções e os desequilíbrios que nascem permanentemente do próprio processo." Compreender a formação de tais possibilidades de acumulação em um dado espaço requer a observação, de acordo com o autor, de três processos, quais sejam: a) o tipo de evolução de organização da produção e da relação dos assalariados com os meios de produção; b) a forma de partilha do valor criado que permite a reprodução dinâmica das diferentes classes e grupos sociais; e c) a modalidade de articulação com as formas não capitalistas de reprodução social, sobretudo quando estas possuem lugar determinante na formação econômica estudada.
} 
Latina, a subordinação da produção ao capital comercial teve um caráter profundamente reacionário, dificultando essas transformações. É sintomático, por exemplo, que, enquanto nos EUA a mecanização crescia rapidamente, no Brasil se "reinventava" a parceria e o colonato para fazer frente à escassez de mão de obra nas lavouras. Daí ser o mais correto afirmar que, além do trabalho assalariado temporário ser um produto do desenvolvimento das forças capitalistas na agricultura (enquanto embrião da formação do proletariado rural) ele é, ao mesmo tempo, resultado da insuficiência e da fraqueza desse desenvolvimento: da insuficiência do capital em submeter as forças da natureza, do ponto de vista técnico; da fraqueza de generalizar essa subordinação, não apenas do ponto de vista formal, mas sobretudo de uma maneira real e ampla, revolucionado a produção agrícola em todas as suas fases.” (GRAZIANO DA SILVA, 1981: 119. Grifo do autor)

Como a passagem acima assinala, Graziano da Silva atribui o "grau" de desenvolvimento das forças produtivas capitalistas no campo a um conjunto de instrumentos que "funcionam" e melhor viabilizam o processo técnico-produtivo. No caso brasileiro, o fato de, em certos momentos da produção, o trabalho humano ser substituído por máquinas, e em outros, apesar de existirem máquinas para substituí-lo, os investimentos necessários para a efetivação de tal substituição ainda não terem ocorrido - dando margem ao surgimento do trabalhador temporário -, demonstra, segundo Graziano, a insuficiência e a fraqueza do desenvolvimento capitalista na atividade agrícola nacional.

Entretanto, tal fenômeno parece apontar ainda para as particularidades que o capital confere à produção agrícola nacional. Isto porque a atividade econômica não é apenas uma relação dos homens com a natureza e com os instrumentos intermediadores, mas também - e sobretudo - uma relação inter-sujeitos. Trata-se, portanto, de uma relação que, por ser econômica, é também cultural e política. É esta interpretação que nos permite compreender o capital como uma relação social com um suporte material, e o capitalismo, por sua vez, como uma forma histórica de organização da produção. Assim, para além do dimensionamento da estrutura técnica de produção, o capital deve ser apreendido como sendo o conteúdo de uma relação social de dominação 
do trabalho materializado (meios de produção, produtos e dinheiro), e de dominação do trabalho vivo que cria valor (força de trabalho). Nesta relação, o trabalhador assalariado, com seu trabalho concreto, transfere para o novo produto a parte do valor dos meios de produção consumidos produtivamente e, ao mesmo tempo, com seu trabalho abstrato, cria um novo valor, materializado na mercadoria que ele mesmo produz.

Entretanto, a composição técnica dos processos de produção de valor não pode servir como parâmetro para análises sobre a consistência de relações capitalistas. Se adotarmos a perspectiva da totalidade concreta, a inadequação deste tipo de análise torna-se ainda mais nítida. Conforme ressaltam Lukács (1992) e Kosík (1976), na dialética marxista, a totalidade concreta se constitui no espaço de objetivação das partes em suas relações com o todo. A análise dialética da relação entre o geral e o específico permite justamente o encontro da totalidade em cada momento particular, guardando de cada momento o seu caráter de momento. Do ponto de vista analítico, portanto, a realidade social pode ser compreendida pela constante tensão entre os momentos parciais e a totalidade ${ }^{5}$.

Esta é a essência da explicação do materialismo dialético, qual seja, a concepção e apreensão dos fenômenos sociais com referência ao singular e ao geral. Empregando tal método interpretação ao problema aqui exposto, podemos compreender o trabalho temporário como forma particular, especificidade histórica do desenvolvimento geral do capitalismo na agricultura. Isto porque o próprio movimento de acumulação se instaura através de relações sociais que são tecidas em bases territoriais, políticas e culturais diferenciadas. É mister, portanto, evidenciar-se a importância de variáveis históricas locais (sejam de caráter social, cultural, político, biofísico etc.) no entendimento tanto do progresso técnico e das relações de trabalho na agricultura, bem como das formas que assumem os padrões de apropriacionismo e substitucionismo industriais; isto é, trata-se de considerar, no sentido weberiano, o milieu econômico que, de maneiras distintas, tenciona o remodelamento das estratégias de acumulação no campo ${ }^{6}$.

\footnotetext{
${ }^{5}$ Neste sentido, Cardoso (1993: 91-92) enfatiza que, "metodologicamente, trata-se de um esforço de elevação do particular para o geral no qual as relações parciais (particulares) vão sendo circunscritas em teias de relações e vão se especificando e determinando de tal modo que a síntese resultante (o todo, a totalidade) apareça, não como amálgama confuso, indeterminado, "geral", mas como um conjunto hierarquizado e articulado de relações. Este conjunto articulado de relações só se alcança por intermédio da produção de conceitos que ponham a nu o modo de relação entre as partes que compõem o todo e as leis de seu movimento."

${ }^{6}$ Em Weber, a noção de milieu econômico supõe a interpretação das relações de processos sociais distintos na caracterização de cenários de sociabilidade. Dentre tais processos, destacam-se a história
} 
Neste sentido, cabe a afirmação de Prado Jr (1977, 99), para quem

“(..) é preciso não confundir 'capitalismo' com tecnologia desenvolvida. Essa confusão é insinuada e estimulada por concepções apologéticas do capitalismo, e toma por padrão de referência o sistema tal como se apresenta nos países altamente desenvolvidos, como os Estados Unidos e na Europa Ocidental. Mas o que caracteriza essencialmente o capitalismo como sistema econômico e social, são as relações de produção e trabalho em que os fatores ou bens de produção, ou que concorram na produção de mercadorias (instrumentos de produção e máquinas, matéria-prima a ser elaborada etc., e particularmente força de trabalho empregada na produção), são mercadorias que se compram e vendem, e privadamente apropriadas: a força de trabalho, pelo trabalhador; as demais, pelo capitalista e empresário da produção. O capitalismo é assim, não importando essencialmente a tecnologia empregada na produção.”

Sob tal perspectiva, a contradição posta por Graziano da Silva sobre a situação do assalariado temporário - que seria, ao mesmo tempo, produto do desenvolvimento das forças capitalistas na agricultura e resultado da fraqueza e insuficiência desse desenvolvimento - é, no âmbito da totalidade, apenas uma contradição aparente, falseada em suas características de manifestação imediata. Isto porque, quando analisado em suas conexões significativas com os interesses de acumulação da moderna agroindústria, este assalariamento temporário revela-se como categoria absolutamente atrelada ao movimento de produção de valor. Em essência, os aspectos relativos à produtividade do trabalho social - que poderia ser incrementada mediante a incorporação de tal ou qual técnica - são expressões materiais do movimento de criação de valor, servindo tão somente para reforçá-lo. A contradição concreta do trabalho temporário é justamente sua manutenção como relação particular no movimento de produção de valor. Ou seja, seu conteúdo contraditório reside em sua dependência para com a manutenção de uma relação de assalariamento que,

política, as características culturais, os atributos de prestígio social, as particularidades da história econômica (que também envolve as características dos grupos sociais, dos atributos ambientais e das relações de propriedade sobre o espaço). Esta noção foi particularmente útil na interpretação desenvolvida pelo autor a respeito da formação do capitalismo Junker nas áreas rurais da Alemanha no final no século 
simultaneamente, o reproduz e o precariza socialmente. Em termos históricos, uma importante expressão desta contradição tem sido o debate recente acerca dos impactos sociais da proibição das queimadas dos canaviais no estado de São Paulo ${ }^{7}$.

O trabalho temporário é uma forma específica de manifestação do desenvolvimento capitalista na agricultura. A hipótese da possível "insuficiência” deste desenvolvimento fundada na análise da resposta social aos impasses locais das diferenças entre os tempos de trabalho e de produção, assume traços positivistas justamente por introduzir na análise noções de mediação e de progressão linear da própria história. Neste sentido, tal como observa Elias (1991) em torno das representações sociais dominantes no processo de conhecimento, o conceito também é expressão das formas como a sociedade se experimenta em momentos históricos específicos. A “insuficiência” supõe o inconcluso, ou seja, o não acabado que é passível de projeção teleológica, previsível, sujeito à regra e que pode ser inequivocamente interpretado sob a perspectiva do devir. Revela, portanto, uma concepção de fenômeno menos atenta à estruturação de certas relações contraditórias de interdependência do que à caracterização de possíveis coerências formais do progresso técnico na agricultura moderna.

Com efeito, o trabalho temporário na agricultura faz parte de uma teia complexa de relações interdependentes que estruturam o modo como o apropriacionismo industrial relacionou-se com a produção agrícola no país. Não só as dimensões econômicas do hiato entre tempos de trabalho e de produção, mas também conflitos de classe relativos às questões fundiárias e à determinação dos direitos trabalhistas no campo, estão envolvidos na construção social do trabalho temporário e de sua expressão simbólica mais marcante, qual seja, a figura do "bóia-fria". Conforme apropriadamente destacado por Silva (1999), os marcos institucionais que reafirmaram, ainda na década de 60, os direitos trabalhistas à força de trabalho rural (com destaque para o Estatuto do Trabalhador Rural, de 1963), contribuíram de modo decisivo para a

XIX, caracterizado pelo alto grau de exclusão social e por sua cultura fortemente autoritária. A propósito, ver Weber (1982).

${ }^{7}$ Como é sabido, o aumento da mecanização das lavouras de cana-de-açúcar - acelerado, dentre outras razões, pela perspectiva de proibição das queimadas como prática de preparo para a colheita - vem ocasionando a dispensa de grandes massas de trabalhadores nas regiões canavieiras de São Paulo. Tal situação tem feito com que sindicatos de trabalhadores rurais e mesmo administrações municipais manifestem severas restrições à regulamentação das queimadas no estado. A rigor, tal situação expõe, de maneira inequívoca, a luta das próprias entidades de representação destes trabalhadores pela manutenção da modalidade de assalariamento temporário na agricultura, ainda que tal relação de emprego os subjugue cotidianamente. A propósito dos diversos interesses dispostos no debate sobre as queimadas de cana crua no estado de São Paulo, ver Gonçalves (2002). 
expansão do trabalho temporário no país na medida em que se restringiram a regular apenas as formas de contratação da força de trabalho permanente, deixando os volantes fora seu espectro de regulação. Tratada como temporária, eventual, a categoria dos "bóias-frias", desprovida então de direitos trabalhistas, tornou-se funcional ao movimento de acumulação na agricultura, posto que passou a representar uma alternativa menos onerosa (dos pontos de vista econômico e de compromisso trabalhista) de emprego da força de trabalho no empreendimento capitalista no campo.

Portanto, o trabalho temporário pode ser adequadamente compreendido como uma das formas sociais produzidas pelo desenvolvimento capitalista da agricultura brasileira, e não expressão de sua suposta inconclusividade. Resulta da emergência de processos econômicos e políticos envolvidos em contradições de classe, expressando parte das especificidades das relações estabelecidas entre trabalho social e propriedade fundiária na sociedade brasileira. Assim como o trabalho escravo, que a despeito do ar de "atraso" permanece articulado às propriedades rurais com perfis indiscutivelmente modernos de produção agrícola ${ }^{8}$, o trabalho volante é circunstancialmente eficiente, em termos de produção de valores excedentes, para a preservação das relações de dominação sócio-política da agricultura modernizada e de sua expressão maior, qual seja, os Complexos Agroindustriais.

Nestes termos, longe de expressar insuficiência presa a lugares específicos, o trabalho temporário compõe o cenário do espaço de fluxos da moderna agricultura nacional. Ou seja, lançando mão dos termos de Castells (2001), o trabalho temporário também integra a organização material das práticas sociais de tempo compartilhado que funcionam por meio de fluxos (espaço com fronteiras físicas frouxas onde se desenrolam a produção, a experiência e o poder na sociedade em rede). Além de alterar de maneira fundamental o significado e a dinâmica dos lugares, sobretudo daqueles lugares de onde partem os migrantes para o trabalho sazonal, este espaço de fluxos propõe novas referências de interpretação do cotidiano do lugar. Isso ocorre, por exemplo, na medida em que estes migrantes constroem suas identidades

\footnotetext{
${ }^{8}$ Nos últimos anos, têm sido recorrente os alertas da OIT (Organização Internacional do Trabalho) sobre o crescimento do trabalho escravo em todo o mundo. No Brasil, em particular, a OIT tem destacado, a partir dos dados do Ministério do Trabalho, que o emprego de modalidades de escravidão e trabalho forçado no país segue fortemente atrelado aos movimentos migratórios de trabalhadores que são efetivamente traficados, pelos gatos intermediários, de regiões com graves bolsões de pobreza, afetadas pelo desemprego sazonal ou pela seca, para empresas agrícolas altamente capitalizadas (OIT, 2002). Dados da Comissão Pastoral da Terra dão conta de que atualmente haveria cerca de 25 mil trabalhadores escravizados no país; a Contag, por sua vez, trabalha com números em torno de 40 mil trabalhadores (SILVA, 2005).
} 
permanentemente em trânsito, buscando reinventar projetos e expectativas para o lugar através da reprodução de suas condições de precariedade no fluxo do emprego temporário.

\section{Considerações finais}

Na tentativa de superar as limitações que a própria natureza impõe à acumulação no campo, o movimento de produção de valores não só cria relações específicas de manutenção e subordinação da natureza e de antigas relações sociais de produção - como, no caso brasileiro, o colonato e a parceria - à sua lógica, como também desenvolve novas relações para a apropriação do trabalho social excedente. Ou seja, tal movimento não só rearticula antigas relações em seu desenvolvimento, mas também desenvolve o moderno sobre bases tradicionais, conservando contradições sociais não como resquícios de "atraso", mas como relações singulares de sua própria modernidade.

$\mathrm{Na}$ medida em que as contradições que sustentam o trabalho temporário na agricultura brasileira são interpretadas como relações características de um modo de modernização territorial e historicamente circunscrito, os processos envolvidos na totalidade do desenvolvimento capitalista da agricultura nacional podem ganhar maior nitidez analítica. Abrindo mão da noção de insuficiência, torna-se possível a compreensão aprofundada da complexa teia de relações sociais que suportam o trabalho temporário como elemento fundamento do apropriacionismo industrial da agricultura nacional. Nesta perspectiva, categorias sociais fundamentais para a compreensão das relações de trabalhos em tempos de alta modernidade - tais como classes sociais, raça/etnia e gênero - podem ser analisadas e dimensionadas no interior desta modalidade específica de emprego da força de trabalho na agricultura, possibilitando assim a complexificação da análise do fenômeno.

Ademais, ao superar a noção de insuficiência, também se criam novas perspectivas quanto à compreensão dos embates políticos envolvidos nas esferas jurídica e mesmo na representação sindical destes trabalhadores temporários. Os demais processos sociais que conferem conteúdo concreto ao fenômeno, como é o caso da migração de trabalhadores das regiões norte e nordeste do país para o trabalho sazonal nas lavouras do sudeste (sobretudo nas lavouras de cana-de-açúcar, no estado de São Paulo), podem ser articulados à análise não mais como formas residuais de organização do trabalho, mas sim como elementos nucleares para a interpretação dos sentidos de 
modernidade de algumas das cadeias agroindustriais de maior densidade política e econômica no país. 


\section{Referências Bibliográficas}

ABRAMOVAY, R. Paradigmas do capitalismo agrário em questão. São Paulo: Anpocs/Hucitec/Ed. Unicamp, 1992.

BENKO, G. Economia, espaço e globalização na aurora do século XXI. São Paulo: Hucitec, 1996.

CARDOSO, F.H. As idéias e seu lugar: ensaios sobre as teorias do desenvolvimento. Petrópolis-RJ: Vozes, 1993.

CASTELS, Manuel La société en réseaux (Tome.1 de L'ère de l'information). Paris : Fayard, 2001.

ELIAS, N. Qu'est-ce que la sociologie?. Paris : Éditions de l'Aube, 1991.

GONÇALVES, D.B. A Regulamentação das queimadas e as mudanças nos canaviais paulistas. São Carlos-SP: RiMa/Fapesp, 2002.

GOODMAN, D., SORJ, B., WILKINSON, J. Da lavoura às biotecnologias: agricultura e indústria no sistema internacional. Rio de Janeiro: Campus, 1990.

GRAZIANO DA SILVA. J. Progresso técnico e relações de trabalho na agricultura. São Paulo: Hucitec, 1981.

GRAZIANO DA SILVA. J. A nova dinâmica da agricultura brasileira. São Paulo: UNICAMP, 1996.

GUIMARÃES, A.P. A crise agrária. 3ª ed.- Rio de Janeiro: Paz e Terra, 1982.

KAGEYAMA, A. et. al. O novo padrão agrícola brasileiro: do Complexo Rural aos Complexos Agroindustriais. Brasília: IPEA, 1990.

KAUTSKY, K. La question agraire: étude sur les tendances de l'agriculture moderne. Paris, Maspéro, 1970.

KOSÍK, K. Dialética do concreto. Rio de Janeiro: Paz e Terra, 1976.

LEFF, E. Epistemologia ambiental. São Paulo: Cortez, 2001.

LUKÁCS, G. A ontologia de Marx: questões metodológicas preliminares. In Lukács Sociologia. José Paulo Neto (org), Coleção Grandes Cientistas Sociais - São Paulo: Ática, 1992.

MARTINS, R.C. A construção social do valor econômico da água: estudo sociológico sobre agricultura, ruralidade e valoração ambiental no estado de São Paulo. Tese (Doutorado). PPG-SEA, Universidade de São Paulo, 2004.

MARX, K. O capital: Crítica da Economia Política (livro I) - Rio de Janeiro : Civilização Brasileira, 1971. 
MARX, K. Introdução à crítica da economia política. Os Pensadores, São Paulo: Nova Cultural, 1987.

MUlleR, G. Complexo agroindustrial e modernização agrária. São Paulo: HUCITEC-EDUC, 1989.

OIT - ORGANIZAÇÃO INTERNACIONAL DO TRABALHO (2002). Relatório global do seguimento da declaração da oit relativa a princípios e direitos fundamentais no trabalho. OIT: Conferência Internacional Do Trabalho. Oficina Internacional Del Trabajo/Secretaria Internacional Do Trabalho, Genebra, 2002.

PRADO Jr, C. A revolução brasileira. $7^{\text {a }}$ edição - São Paulo: Hucitec, 1977.

SILVA, M.A.M. Errantes do fim do século. São Paulo: Editora Unesp, 1999.

SILVA, M.A..M. Trabalho e trabalhadores na região do "mar de cana e do rio de álcool” Agrária - Revista do Laboratório de Geografia Agrária (DG/FFLCH/USP), n.2, pp.02-39, São Paulo, 2005.

SZMRECSÁNYI, T. Pequena história da agricultura no Brasil. São Paulo: Contexto, 1990.

VEIGA, J. E. $O$ desenvolvimento agrícola: uma visão histórica. São Paulo: Hucitec/Edusp, 1991.

WEBER, M. Capitalismo e sociedade rural na Alemanha. In: Ensaios de sociologia. $5^{\text {a }}$ ed. Rio de Janeiro: Zahar Editores, 1982. 